\title{
Deus ex machina e o Deus absconditus na poética de R.S. Thomas
}

Fabrício Tavares Moraes ${ }^{1}$

\section{Resumo}

O presente artigo busca analisar a forma como o poeta galês R.S. Thomas interpreta e harmoniza algumas tensões históricas, por meio de sua unidade poética. Desse modo, no entendimento de Thomas, o sagrado, o secularismo, a tecnocracia e a dessacralização ocasionam rupturas no continuum histórico, e somente são alinhavadas mediante a poesia. Além disso, explora-se o modo como, ao longo da obra do poeta, as questões relativas àtranscendência se relacionamcomocircunstancialeo imanente, assim como os paralelos recorrentes entre eternidade e história.

Palavras-chave: Poesia europeia; transcendência; história; R.S. Thomas

\section{Abstract}

This paper aims to analyze the way in which the Welsh interprets and harmonizes some historical tensions by means of his poetical unity. Thus, according to Thomas's conception, the sacred, the secularism, the technocracy and the desacralization brings forth ruptures in the historical continuum, which are only aligned through poetry. Furthermore, we explore how, throughout the poet's works, issuesconcerning transcendence

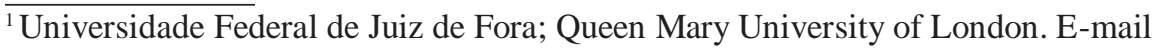
fabriciotavaresm@gmail.com 
relates to the circumstantial and the immanence, and also the recurrent parallels between eternity and history.

Keywords: European poetry; transcendence; History; R.S. Thomas

\section{Introdução}

De modo geral, a poesia e a apreensão histórica gozam de uma relação ambígua, quando não conturbada, devido, em parte, às formas conflitantes de ambas. Isto é, por um lado, a poesia pauta-se na cadência do ritmo, na flutuação prosódica e recorrência das rimas - e não somente no universo simbolista em que, conforme a célebre frase de Verlaine, a "música vem antes de tudo", mas na própria estrutura poética que, semelhante aos mitos, tende a ser cíclica. Analisada por esse viés, o poema é, segundo Octávio Paz, "uma máquina que produz anti-história, ainda que o poeta não tenha essa intenção (PAZ, 1991, p. 11)", não porque nega a história enquanto processo ou prisma interpretativo da realidade, mas sim porque "a operação poética consiste em uma inversão ou conversão do fluir temporal; o poema não detém o tempo: o contradiz e o transfigura" (PAZ, 1991, p. 11).

Por outro lado, é notório que toda poética, por mais idiossincrática que seja, insere-se numa unidade social, com a qual compartilha a linguagem, alguns símbolos e valores, de maneira que, conforme propõe todo e qualquer método da história da literatura, é possível relacionar ou situar, embora nem sempre de forma precisa, um autor ou poeta a determinados movimentos estéticos ocasionados ou perpetradores de eventos históricos. Afinal, "o poema é um objeto feito da linguagem, dos ritmos, das crenças e das obsessões deste ou daquele poeta, desta ou daquela sociedade" (PAZ, 1991, p. 11).

Não obstante a fertilidade gerada por essa tensão entre poema e história, o fato é que, conquanto o material poético (as palavras, 
sons, imagens e símbolos, etc.) estejam localizados e fazem parte da constituição de uma sociedade histórica, a forma ou modo de composição, contudo, são arredios a toda historiografia. Mais uma vez Octavio Paz resume a questão com as seguintes palavras: "[O poema] é o produto de uma história e de uma sociedade, mas o seu modo de ser histórico é contraditório" (PAZ, 1991, p.11)

Desse modo, reafirmando um pressuposto talvez já incontroverso, pode-se dizer que toda análise sensata de um conjunto poético de determinado autor necessariamente leva em conta essa tensão, pois ao mesmo tempo em que sua poética pode e deve refletir, em certo nível, os impasses e contradições de um momento ou mesmo uma era histórica específicos, ainda quando se apresentem de maneira vaga e parcialmente indiscernível, ao mesmo tempo o processo de composição e a forma final do poema subsume as percepções e estruturas permanentes que perpassaram esses instantes históricos. É o caso, por exemplo, de Omeros, de Derek Walcott, poética que, embora esteja fundamentada, materialmente falando, nos termos, símbolos e mesmo musicalidade caribenhas, vale-se, contudo, da estrutura épica de um Homero, Virgílio e outros.

Nesse sentido, o presente artigo propõe uma análise sucinta sobre o modo como se dá a relação entre história e transcendência na poética do galês R.S. Thomas (1913-2000), poeta indicado ao prêmio Nobel em 1995, e tido, até o ano de sua morte, como um dos poetas mais influentes e originais da Europa, especialmente pelo seu tratamento singular de questões como a espiritualidade em meio à secularização. De modo resumido, a análise pretende debruçar-se sobre o modo como os elementos da chamada supra-história (Karl Barth) e a concretude da história, ou, dito de outro modo, como a poesia se configura como ponto de convergência entre elementos que transcendem a história e, no entendimento de Thomas, fundamentam-na, e as vicissitudes, limitações e exigências das contingências humanas. 
Numa primeira análise, a poética de R.S. Thomas retoma a tradição dos grandes "poetas metafísicos" do Reino Unido, em especial George Herbert e John Donne, não somente devido aos valores transcendentais engastados em sua poética, mas também devido à convergência, nas palavras de T.S. Eliot, de uma poesia que aproxima intelecto e emoção. No entanto, levando em conta o entorno histórico da obra, os poemas de Thomas, diferentemente das composições dos poetas metafísicos, são, por vezes, uma voz dissonante no deserto, um ponto ínfimo de incidência teológica em meio à atmosfera secularizada.

Entretanto, contrariamente do que se imagina, a poética de Thomas não advoga um confessionalismo alheio às vicissitudes ou mesmo tensões que conduziram àquilo que Dan Cupitt chama de a "era depois de Deus"; pelo contrário, conforme analisaremos no presente artigo, a obra do poeta galês se desdobra em duas perspectivas sobre a composição poética e a história.

Em primeiro lugar, a cisão dentro da própria história, pois R.S. Thomas, além da contraposição das ruínas e catedrais históricas de sua nação com os espaços modernizados, retoma sempre a ideia do descompasso entre as respectivas sensibilidades das gerações, mais especificamente o abismo que o separa da atual "era da máquina”. Neste aspecto, deparamo-nos com a questão da legitimidade da poesia (e do poeta) com as demandas e circunstâncias históricas; dito de outro modo, a recorrentequestãoacerca da açãoou passividade datécnicapoéticaperante os acontecimentos e crises políticas, sociais e econômicas, que o poeta vivencia, enquanto indivíduo integrante de uma sociedade. Em segundo lugar, temos as relações ambíguas da poesia coma transcendência, no qual a existência histórica do homem se confronta com os ditames e princípios a-históricos, isto é, eternos.

Ambas as perspectivas, entretanto, convergem em determinados pontos, visto que, no universo poético de R.S. Thomas, imanência e transcendência não são exatamente polos de oposição. Pelo contrário, a 
eternidade somente se faz conhecida por meio da concretude dos eventos humanos, de modo que estes, por seu turno, assumem sempre um caráter que ultrapassa a mera contingência.

Desse modo, nas duas subseções seguintes, abordaremos o modo como Thomas explora cada uma dessas perspectivas, respectivamente, em sua obra poética.

\section{Deus ex machina}

Em seu poema "Here" [Aqui], a cisão dentro da própria história se faz presente não somente nas dores e decepções de um ancião, bem à semelhança de "Lamentation of a Old Pensioner", de Yeats, mas também resvala na questão do impacto ou incisão da transcendência na história. Analisemos detidamente esses elementos:

I have nowhere to go.

The swift satélites show

The clock of my whole being is slow.

It is too late to start

For destinations not of the heart

I must stay here with my hurt ${ }^{2}$ (THOMAS, 2000, p. 120)

Com a leitura do poema, percebemos que a consciência de senilidade do eu-lírico não advém de um confronto da transitoriedade humana com

$\overline{{ }^{2} \text { Em tradução livre: }}$

Não há lugar que me acoite

Mostra os céleres satélites:

Certo é que o relógio de meu ser hesite,

É tarde demais para partidas

Que não são ao coração devidas.

Devo ficar aqui com minha ferida. 
a eternidade, mas sim da diferença desproporcional entre a velocidade das tecnologias (os satélites) e o ritmo vagaroso e limitado da condição humana. Essa diferença é ainda mais enfatizada por meio da opção dos substantivos: o satélite, tecnologia espacial e digital, em contraposição com o relógio, artefato mecânico e imóvel; e também dos adjetivos: swift [célere] e slow [vagaroso]. Em toda sua obra, a máquina é vista como um intruso no plano da história, e por isso mesmo um elemento catalisador ou inaugurador de um novo momento, no mais das vezes terrível. Ora, não há aqui nada de ludismo ou do caráter dos "apocalíticos" de que Umberto Eco tratou tão pormenorizadamente. Antes, conforme diz William V. Davis, em sua obra R.S. Thomas: Poetry and Theology:

Máquina, homem e Deus são parte de um continuum, uma ordem progressiva que se move para frente e para trás por meio de seu constituinte central, isto é, o homem. E visto que tanto $o$ Deus (como Thomas geralmente o designa) e a máquina estão silenciosos, ao homem é deixado combinar, ordenar, misturar e encaixar todas as coisas; o homem é deixado, por conta própria, a tentar compreender o continuиm e seu lugar apropriado nele ${ }^{3}$ (DAVIS, 2007, p. 118).

O que Thomas propõe, portanto, é uma espécie de criação serial, um elo que perpassa gradativamente Deus, homem e máquina. A história, portanto, diferentemente do pensamento iluminista, não conduz ao esclarecimento, mas ao mutismo. Pois se, de certo modo, Thomas retoma o conceito de Lutero do Deus absconditus, o Deus que se oculta, seus poemas exploram também, num perfeito jogo conceitual, um Deus ex machina que jamais se revela. Dito de outro modo, a máquina,

\footnotetext{
${ }^{3}$ No original: "machine, man, and God are all part of a continuum, a progressive order moving backward and forward through its central constituent, man. And since both the God (as Thomas so often calls him) and the machine are silent, man is left to combine, order, mix and match everything; man is left, on his own, to attempt to understand the continuum and his own place in it" (DAVIS, 2007, p. 118).
} 
embora criação do homem, torna-se muda, uma potência com a qual não se estabelece comunicação. O que é curioso, visto que um dos grandes fatores da transformação moderna é precisamente os chamados meios de comunicação em massa. Em seu poema "Counterpoint", o poeta efetivamente dirige seus questionamentos também à máquina:

Is there a contraceptive for the machine, that we may enjoy intercourse with it without being overrun [...] as we ... go up into the temple of ourselves and give thanks that we are not as the machine is (THOMAS, 2000, p. 54) ${ }^{4}$.

A questão subjacente aos versos é: nossa relação com a máquina é fértil ou estéril? A princípio, a máquina representa não apenas o alívio das dores do trabalho, mas principalmente o domínio sobre a natureza. A técnica, tomada aqui no sentido de capacidade efetiva deconsecução de um plano, certamente manipula os fenômenos, e neste sentido é fértil. Porém, conforme diz os versos do poema, por que rendemos graças, quando adentramos o templo de nosso ser, pelo fato de não sermos como a máquina?

Para Thomas, conforme dito acima, a máquina, ou mais especificamente a ascensão da máquina, delimita um ponto na história, em que uma parcela da criação humana separa-se dela, como, no

\footnotetext{
${ }^{4}$ Em tradução livre:

Há algum contraceptivo

para a máquina, de modo que possamos gozar

com ela o intercurso sem sermos invadidos [..]

enquanto

... vamos para cima

aos nossos próprios templos

e damos graças porque não somos

tal como a máquina é?
} 
entendimento de Thomas, o homem separou-se de Deus. Há algo aqui semelhante ao conto de Kafka, "A colônia penal", no qual uma máquina executa uma sentença fria escarificando várias vezes o veredicto na carne dos condenados, até que seu corpo seja desfeito. A históriaé pontuada pela cisão entre Deus e homem, e, presentemente, entre homem e máquina. A poesia, por sua vez, é a instância que, diferentemente da história, e por meio de seu poder condensador (Ezra Pound) entrelaça num continuum a relação entre esses três elementos.

Como se sabe, o positivismo de Auguste Comte propunha uma evolução histórica e cultural na mentalidade dos povos, que se manifestava em três domínios, num progresso imparável: a religião, a metafísica e a ciência (ou técnica). Thomas, porém, por meio de seus poemas, demonstra que também a técnica e a máquina chegaram num impasse, no qual a história, segundo o modelo positivista, é interrompida.

Em certo poema, Thomas traça um paralelo entre a crucificação de Cristo e a crucificação do homem. Em ambas as crucificações, o criador vê-se repudiado pela sua criatura; no primeiro caso, Deus é escarnecido pelos homens, no segundo, o homem é zombado desafiadoramente pela máquina:

If you were so clever

as to invent me, come down

now so that I may believe (THOMAS, 2000, p. 54).

O poema alude ao momento da crucificação, conforme relatado nos Evangelhos, quando alguns presentes troçavam de sua declaração como Filho de Deus, e exigiam, ironicamente, que descesse da cruz a fim de comprovar sua divindade. Desse modo, por meio desse paralelo, Thomas, de certo modo, apresenta a ruptura histórica ocasionada pela

\footnotetext{
${ }^{5}$ Em tradução livre:

"Se fostes tão sagaz

Em inventar-me, desça

Agora para que eu possa crer"
} 
relação do homem com a máquina. Em outras palavras, assim como a vida e crucificação de Cristo cria um novo momento histórico, também a máquina, zombando do homem agora crucificado, demarca um outro momento ou era: a morte do homem. Todavia, conforme dito, não é porque a máquina substitui o homem, antes, o homem padece pela mudez de seu Criador e de sua criatura. Isolado no "relógio do ser", a máquina serve simplesmente de memento mori.

Peter Vermeulen, em sua obra Contemporary Literature and the Death of the Novel, assinala para as relações entre a ideia do antropoceno (ainda que controversa no meio científico) e a morte do romance ou da literatura. Para o autor, a percepção de que o homem age não somente como força histórica, mas também como força geológica sobre o mundo, gera um conjunto inteiramente novo de pressupostos e relações entre suas criações (incluindo aqui a tecnologia e a arte) e a história.

No seu entendimento, o homem tornou-se um "deus de detritos", cuja ação no mundo é vista não necessariamente como transformação ou cultura, mas também como presença residual. Isto necessariamente exerce um impacto sobre o espaço e história humanos, bem como na própria definição do humano. Nas palavras de Vermeulen: “Esse encontro com uma escala radicalmente não-humana inspira uma visão de homens beligerantes sendo devorados pelas tecnologias que inventaram para se protegerem, e a vida humana sendo reivindicada pela história natural que tentara dominar" (VERMEULEUN, 2015, p. 149).

Por fim, a máquina não é uma antítese ao homem; na verdade, ela reaparece a todo momento na obra de Thomas como "um símbolo da sociedade crescentemente mecanizada que ele percebeu que estava usurpando a vida do espírito" (DAVIS, 2007, p. 29). Na poesia, contudo, retomando o pensamento de Octavio Paz, o ideal maquinário é dissolvido na percepção da unidade do real. Se as tensões entre homem, máquina e Deus não se harmonizam no contínuo histórico, criando, antes, rupturas intransponíveis, na poesia, contudo, os três são integrados por meio 
da analogia e da unidade poética. Davis resume essa percepção com as seguintes palavras:

Em resumo, como Thomas parece sugerir - e, creio ser, finalmente, o ponto crucial de toda essa história de seu uso da metáfora da máquina - que a máquina é para o homem o que o homem é para Deus. Portanto, se a máquina reconhece a soberania do homem, e se o homem reconhece a soberania de Deus, então, e somente então, haverá alguma esperança para um acordo pacífico entre criatura e criador - quer pensemos no relacionamento entre Deus e homem ou entre homem e máquina. Somente assim haverá esperança para "salvação" - em termos da vida do homem na terra, de seu relacionamento com a máquina, e de seu relacionamento com Deus ${ }^{6}$ (DAVIS, 2007, p. 119).

Desse modo, na visão de Thomas, a história é, portanto, a narrativa de grandes rupturas (Deus e homem, homem e máquina) e afastamentos, ao passo que a poesia é a instância de súplicas e reconciliações, ainda que, semelhante ao seu modelo teológico, paute-se por vezes no sacrifício.

\section{Deus absconditus}

Max Scheler, num momento histórico crítico em que os pensadores buscavam fundamentar ou balizar a identidade humana em algum dos

\footnotetext{
${ }^{6}$ No original: "In short, as Thomas seems to suggest - and I think it is, finally, the crux of this whole history of his use of the metaphor of the machine - the machine is to man as man is to God. Therefore, if the machine acknowledges man's sovereignty, and if man recognizes God's sovereignty, then, and only then, will there be some hope for a peaceful accommodation between creature and creator - whether we think of the relationship as that between God and man or between man and machine. Only then will there be some hope for 'salvation' - in terms of man's life on earth, in terms of his relationship with the machine, and in terms of his relationship with God" (DAVIS, 2007, p. 119).
} 
aspectos de sua ação no mundo (como os existencialistas, por exemplo, que fundamentaram a essência do homem na sua liberdade), apresentou uma tese, sob certo aspecto, destoante do pensamento materialista então vigente.

EmAPosiçãodo Homemno Cosmos, Scheler, lançandoasbases desua antropologia filosófica, afirma que o homem se diferencia dos demais entes não somente por sua autoconsciência, mas também por sua "abertura de mundo". De acordo com suas palavras:

Mas o centro a partir do qual o homem empreende os atos de objetivação de seu corpo e de sua psyche, tornando objetivo o mundo em sua plenitude espacial e temporal, não pode ser ele mesmo uma "parte" desde mundo e também não pode, por conseguinte, possuir nenhum lugar qualquer e nenhum tempo qualquer determinados: ele só pode estar colocado no fundamento ontológicomais supremo (SCHELER, 2003,p.45).

Em resumo, a transcendência, ou a capacidade transcendental, é, segundo Scheler, a marca distintiva do homem, o qual necessariamente anseia pelo fundamento ontológico mais supremo, ou, nas palavras de Aristóteles, o motor imóvel, ou o pensamento do pensamento. A poética de R.S. Thomas retoma alguns elementos da teologia cristã, mas como já dito, não somente dilata-os ao ponto da ruptura como também refaz a tradição teológica, ora secularizando-a, ora santificando, por assim dizer, alguns aspectos seculares modernos. Umexemploé suaobsessãocomaspequenas capelas, isoladas nos rincões de seu País de Gales, em contraposição aos louvores às catedrais presentes na obra de poetas românticos.

Przemysław Michalski, num ensaio sobre a obra de R.S. Thomas, intitulado "The Churches and Chapels of Ronald Stuart Thomas", assinala a presença maciça dessas pequenas igrejas. Destarte, o lamento poético de Thomas geralmente não se dá dentro das grandes catedrais - hoje em parte esvaziadas de seu conteúdo sagrado e concebidas apenas como monumentos arquitetônicos ou sítios para turismo -, mas nos recintos 
ignorados também pelos homens. Segundo Michalski, "Thomas tem sido geralmente chamado de um poeta do Deus oculto, mas ele também é um poeta do silêncio e da voz que se cala, qualidades que estão em completa sintonia com o tema de sua obra"7 (MICHALSKI, 2014, p. 83).

Retomando o poema Here, por exemplo, vemos essa contraposição entre a história humana e aquilo que Hans Urs von Balthasar chamava de teodrama, isto é, o desvelamento do plano eterno divino, o desenrolar da história da salvação. Para Thomas, o homem é uma espécie de ponto de convergência entre a "eternidade" e as vicissitudes da história, os eventos mais corriqueiros e o cotidiano. Desse modo, há uma ambiguidade típica do autor, pois ao mesmo tempo em que cada instante reveste de uma aura transcendente, uma vez que indica e aponta para algo superior e anterior, há também uma banalização da eternidade, já que ela gradativamente dilui seu aspecto absoluto nas condições relativas e circunstanciais do cotidiano. Os seguintes versos expressam essa ambiguidade:

There is blood in my veins

That has run clear of the stain

Contracted in so many loins.

Why, then, are my hands red

With the blood of so many dead?

Is this where I was misled?

Why are my hands this way

That they will not do as I say?

Does no God hear when I pray?8 (THOMAS, 2000, p. 120).

\footnotetext{
${ }^{7}$ No original: "Thomas has been often called a poet of the hidden God, but he is also a poet of silence and of a hushed voice, which qualities are well attuned to the subject matter of his work" (MICHALSKI, 2014, p. 83).

${ }^{8}$ Em tradução livre:
}

Emminhas veias sangue deslancha,

Que corre limpo das manchas

Contraídasem tantas barganhas. 
O poema se conduz em duas perspectivas paralelas - a do Cristo e do homem. Os "dedos encarnados/ com sangue de tantos finados" [hands red/ With the blood of so many dead?], ou o "sangue que corre limpo das manchas" [Blood...That has run clear of the stain], podem ser lidos tanto como referências às vicissitudes humanas quanto ao sacrifício sui generis de Cristo, cujas mãos portam em si o sangue dos demais homens. O sentimento ambíguo tornase ainda mais agudo quando o eu-lírico indaga se Deus escuta ou não suas súplicas, pois neste ponto reside um dos cernes da poesia de Thomas. Afinal, a despeito das aparências, sua obra suprime precisamente $\mathrm{o}$ abismo entre a condição humana e a essência divina; assim, o lamento de Cristo - "Deus meu, Deus meu, por que me desamparastes?" - é o próprio Deus valendose das palavras de Davi, um homem, para expressar o espanto para com seu próprio silêncio, lamento esse que é, aqui no poema, transmutado no verso "Não ouve Deus quando o suplico?" [Does no God hear when I pray?].

A resposta da transcendência é o silêncio absoluto, o Deus absconditus, como supracitado. Isto, porém, não implica em agnosticismo, ou numa supressão do eterno na história. Pelo contrário, o silêncio na poética de R.S. Thomas não é o vazio ou o vácuo semântico, mas precisamente o oposto - é a instância prenhe de sentido, o espaço que tanto precede quanto se sucede à voz. Em suma, é o estado de coisas anterior e posterior ao Verbo Divino: antes da criação e após sua ressurreição, o silêncio é a ânsia da realidade em reverberar novamente a palavra primordial. Em seu poema "Alive" [Vivo], percebemos que o silencia, ou escuridão, é a instância mesma da revelação no estrato histórico:

Por que estes dedos encarnados

Com sangue de tantos finados?

Foi cá que me tornei desgarrado?

Por que minhas mãos deste tipo,

Que não agem quando me aplico?

Não ouve Deus quando o suplico? 
The darkness

is the deepening shadow

of your presence: the silence a

process in the metabolism

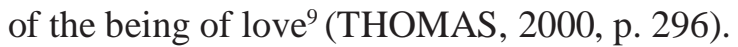

Dando novas nuances ao imaginário teológico, Thomas inverte a ordem genesíaca que afasta as trevas por meio da luz (fiat lux) e da palavra divina, propondo agora a manifestação divina na penumbra e no silêncio. Isto é, os elementos da imanência (silêncio e trevas) tornam-se, na pena poética de R.S. Thomas, instâncias de intrusão da transcendência na história humana. Em “Abercuawg”, por exemplo, em versos memoráveis, o poeta diz: "I am a seeker/in time for what which is/ beyond time, that is everywhere/ and nowhere; no more before than after" ${ }^{10}$.

William A. Davis afirma que, transitando entre as demandas históricas e os princípios eternos, R.S. Thomas retoma a tradição dos grandes poetas e escritores que realizam suas jornadas ou peregrinações, por exemplo, Dante, Milton e Bunyan. Segundo suas palavras, "em essência, a idade da peregrinação constitui uma teodiceia do século XX, tal como Dante e Milton fizerem em suas respectivas épocas" (DAVIS, 2007, p. x). Portanto, ao mesmo tempo em que temos em sua poética o sentimento de mistério de um São João da Cruz, encontramos, de igual modo, a angústia cética ou racionalista das grandes teodiceias dos pensadores iluministas.

${ }^{9}$ Em tradução livre:
A escuridão
é profunda penumbra
de tua presença; o silêncio, um
processo no metabolismo
do ser de amor.
${ }^{10}$ Em tradução livre:
Sou um caçador,
no tempo, daquilo que está
além do tempo, que está em toda parte
e em parte algum; não mais antes do que depois. 
Por fim, podemos afirmar que, no universo de Thomas, a história é o domínio de expiação do eterno, na medida em que o mundo é não somente "o palco para a glória de Deus" (Calvino), mas também o patíbulo sacrificial da Divindade. Para Thomas, citado por Davis, "poesia é religião, religião é poesia"" (DAVIS, 2007, p. 9); seguindo o pensamento de Wallace Stevens, grande influência sobre a obra de Thomas, ambas, religião e poesia, são grandes forças culturais que não apenas interpretam, mas também moldam a história.

\section{Considerações finais}

AnalisandoaobradeR.S.Thomas, talvez, numprimeiro momento, surpreenda-nos fato de que nestaera secularizada, parafraseando acélebre frase de Adorno, ainda sejam possíveis as manifestações poéticas marcadas ou influenciadas por tons espirituais ou religiosos, depois dos horrores políticos do século XX. Afinal, se é verdade que, como já afirma André Malraux, "vivemos na primeira civilização agnóstica-e possivelmente a última civilização", talvez a transcendência aterrorize pela sua dificuldade em satisfazer nossas demandas contingências concretas deste século.

Todavia, qualquer um que se disponha, de bom grado, a analisar as raízes espirituais de poetas modernosreconheceráneles a ânsia metafísica, ou mais especificamente, religiosa. Não somente pela avidez com que um Yeats, Pessoa, Mann se voltavam para o vigoroso substrato pagão da Europa, mas também com a recorrência da tradição judaico-cristã e seus elementos em Eliot, Faulkner, Joyce, Kafka, Beckett. Ao mesmo tempo, porém, esses elementos religiosos e míticos foram utilizados para a formação de uma nova hermenêutica histórica, na qual se interpreta a política e as revoluções sociais por meio de símbolos metafísicos (Mensagem é uma narrativa mítica e espiritual de Portugal, por exemplo);

"No original: "poetry is religion, religion is poetry" (DAVIS, 2007, p. 9). 
de modo que poesia e história, ainda quando aparentemente discordantes, fertilizam-se mutuamente.

A poética de Thomas, especificamente, embora paute-se no silêncio e (parafraseando uma obra medieval) e na nuvem do não-saber, diverge da tradição apofática, que percebe Deus por meio da via negativa, porque integra em sua essência o sentimento de desamparo oriundo da exaustão do humanismo ocidental, bem como um senso de irrelevância ou impotência do discurso da fé num mundo que lhe é cada vez mais hostil. Portanto, embora tratando de temáticas religiosas, sua poética é profundamente histórica. E, sendo profundamente histórica, transcende as contingências, instalando-se na permanência própria da literatura.

\section{Referências}

DAVIS, V. William. R.S. Thomas: poetry and theology. Waco/Texas: Baylor University Press, 2007.

MICHALS KI, Przemysław. "The Churches and Chapels of Ronald Stuart Thomas". Religious and Sacred Poetry, n. 3(7) Julho-Agosto-Setembro 2014. p. 83-97.

PAZ, Octavio. O arco e a lira. 2.ed. Rio de Janeiro: Nova Fronteira, 1991.

SCHELER, Max. A posição do homem no cosmos. Rio de Janeiro: Forense Universitária, 2003.

THOMAS, R.S. Collected Poems 1945-1990. London: Phonix, 2000.

VERMEULEN, Pieter. Contemporary Literature and the Death of the Novel. Hampshire: Palgrave Macmillan, 2015. 
Revista Leitura V. 2 no 57 - jul/dez 2016 - Poesia e História 